\title{
Perspectives on the human dimensions of coral restoration
}

\author{
Authors: \\ Dr Ross Westoby, Griffith University (r.westoby@griffith.edu.au) \\ Prof. Susanne Becken, Griffith University (s.becken@griffith.edu.au) \\ Ana Prieto Laria, Griffith University (ana.prieto.laria@gmail.com)
}

Title: Perspectives on the human dimensions of coral restoration

\begin{abstract}
Coral reef systems are at the point where passive restoration measures may have to be complemented by active restoration to protect global reefs. No longer is habitat conservation enough with the level and frequency of reef disturbance. This review explores the ecosystems-based adaptation (EbA) approach of active coral restoration, with people at the centre of analysis. This paper undertakes a perspective review that collated $(n=37)$ academic papers and develops a 'Human Dimensions of Coral Restoration Technology Adaptation' framework that helps position the wide range of human dimensions of coral restoration studies. Seven phases were considered including assessing risks, assessing cost/benefits, understanding the socio-cultural context, implementing and technology transfer, managing conflict, and maintaining success and scale-up of coral restoration. With every new restoration technology, calculating the micro and macro risks of such interventions is critical, followed by weighing up opportunity costs of such new technologies. People in situ hold the power to shape these restoration projects including the scientists envisioning these interventions, communities at grassroots, leaders that act as gatekeepers and businesses and tourists alike. Stakeholder management as well as the enabling governance arrangements, are also critical strengthening opportunities to managing any potential underlying conflict that is possible between stakeholders.
\end{abstract}

Key Words: coral gardening; ecosystem-based adaptation (EbA); global reefs; reef restoration; stakeholders 


\section{INTRODUCTION}

Coral reef ecosystems are amongst the most productive systems on earth and provide habitat to over a million species (Hoegh-Guldberg et al. 2018). In addition, they deliver invaluable ecosystem services, such as food and coastal protection (Wilkinson 2004), tourism and recreational opportunities (Brander et al. 2012), and intangible benefits such as identity and social and cultural connections (Westoby and McNamara 2019). Yet, despite their value, anthropogenic impacts and pressures placed on coral reefs such as overfishing, pollution and coastal development have risen exponentially over the last forty years. Coral bleaching is a growing catastrophe for reefs (Hughes et al. 2017a; Sully et al. 2019) and the rate of decline of reefs has been accelerating over the last decade (Hoegh-Guldberg et al. 2018). With the last forty years of pressure, such as overfishing and pollution, coupled with warming waters due to carbon dioxide being emitted into the atmosphere, the reefs are in a rapid decline (Morrison et al. 2019). The sheer magnitude of the problem has even called into question whether systems such as the Great Barrier Reef will survive such pressures in the future (Heron et al. 2018).

Multiple approaches are being taken to reduce pressure off coral reef ecosystems or adapt to inevitable changes. Traditionally, marine conservation has focused on habitat maintenance and management, but more recently active interventions into coral reef ecosystems have been advanced (e.g. Rinkevich 2014), leading some experts to conclude that a multi-pronged approach is required to ensure the long-term health of reefs globally (Van Oppen et al. 2017; Possingham et al. 2015). Chronic or repeated disturbances to reefs are placing pressures on ecosystems beyond natural recovery thresholds in many locations, requiring a move beyond just passive conservation to more active interventions (Boström-Einarsson et al. 2020). Coral restoration is one intervention that has gained momentum to assist the recovery of degraded or destroyed coral ecosystem. In a review of 329 coral restoration case studies around the world, Boström-Einarsson et al. (2018) identified different types of intervention, with the most common ones relating to coral gardening (transplantation of coral fragments involving a nursery plus transplantation phase), direct transplantation (e.g. using broken coral after a storm to transplant them without a nursery phase), and artificial reefs.

Coral restoration is a form of Ecosystem-based Adaptation (EbA), meaning it rebuilds natural capital and ecosystem services to adapt to environmental change and addresses the critical links between sustainable resource management, biodiversity and climate change. Its central purpose is to preserve and enhance ecosystems, using a broad suite of tools, to enable cobenefits to mitigate and adapt to climate change (Munang et al. 2013: 27). The main concepts of EbA are to focus on community scale, be participatory and involve multiple stakeholders. The fundamental idea of EbA is to deliver co-benefits, whilst managing trade-offs. It can be enabled by appropriate governance arrangements that supported inclusive approaches and at the same time build on robust evidence base (Nalau and Becken 2018). Coral restoration has gained traction amongst donor agencies who see this intervention as an opportunity to protect or restore ecosystem resilience, whilst delivering social benefits to local communities (e.g. USAID 2017). Conceptualising coral restoration as part of the growing EbA knowledge field aligns well with the aim of this article to understand the human dimensions of this marine ecosystem intervention.

Whilst a burgeoning research field with a significant increase in publications in the last 10 years, and with some success in practice at least in the short term and at a small scale (Boström-Einarsson et al. 2018), active coral reef restoration is not without controversy (Obolski et al. 2016). Some marine scientists caution that restoration detracts from 
addressing the root causes of marine degradation and loss in coral cover (e.g. Hughes et al. $2017 \mathrm{~b}$ ). In contrast, supporters consider restoration as a necessary mechanism to protect or recover endangered coral species as well as marine biodiversity that now has insufficient time for recovery between disturbance events (Anthony et al. 2017). It has also been suggested that social benefits might derive from projects that involve citizens or local communities (Marshall et al. 2012).

The first ever reference to coral restoration, was Maragos (1974) who developed a method to kick start the recovery process for reefs through coral transplantation. Maragos and latter work by Gomez (1983) in the Philippines cited the need for active coral restoration as a response to declining reefs due to anthropogenic change over three decades ago. Gomez's (1983) paper traced humans as central to the problem and thus also pivotal to the solution. Despite this early recognition, and evidence that many restoration projects are poorly designed and do not facilitate adaptive learning (Boström-Einarsson et al. 2018), social science perspectives and papers, with the exception of socio-cultural benefits of coral restoration (Hein et al. 2019), are generally scarce in the field (Lirman and Schopmeyer 2016; Kittinger et al. 2016).

At times of fast changing marine environments, and considerable Government investment into active restoration (Great Barrier Reef Foundation 2018) it is pertinent to take stock of social science-informed knowledge and research activity that vitally informs decision making, und ultimately could determine failure or success of individual projects. The primary objective of this study, therefore, is to present a review of academic peer-reviewed literature that explores the human dimensions of active coral restoration, to highlight the key knowledge in this emerging field and potential gaps, and whether the literature provides opportunities to develop a framework for analysis. Potential challenges and points of contestation will be identified and evaluated with respect to future research agendas.

\section{METHOD}

\subsection{Search strategy}

The review process followed Crisps' (Crisp 2015) three fundamental review principles. First, explicit inclusion and exclusion criteria were established. Second, each collected paper was objectively reviewed to determine its inclusion or exclusion. Lastly, when papers required subjective judgment for inclusion or exclusion (e.g. the extent to which a natural science paper contained sufficient social science insights) then the whole original text of the paper formed the basis of inclusion and exclusion. Given that a wide range of disciplinary backgrounds informs research on coral restoration it became obvious that the terminology to describe this adaptation measure varied. To ensure all relevant papers were gathered, the search was iterative and new key words were added as they emerged in papers or on project websites (e.g. referred to in papers). Artificial reefs and shipwrecks were excluded from the review, as these have a distinct body of separate work attached to them which focuses on providing a rough and stable artificial substratum in which marine organisms including fish and corals can colonise and habitat ( $\mathrm{Ng}$ et al. 2017).

\subsection{Review method}

A review was performed using a methodology similar to the systematic quantitative review techniques outlined by Pickering and Bryne (2014) and Pickering et al. (2015). This method has been found to be reliable and robust in areas that cross the natural and social sciences 
(Guitart et al. 2012; Steven et al. 2011; Turner et al. 2018; Nikulina et al. 2019). During the first stage all papers were in the search results $(n=487)$. Through the screening stage, duplicates were removed, and all papers were screened using their abstracts to determine if the paper focused on the human dimensions of coral restoration $(n=37)$. From that process the majority were excluded $(n=318)$ and 60 papers were deemed to contain relevant insight into the human dimensions of coral restoration. In the eligibility stage, the full texts of the 60 papers were assessed to determine inclusion or exclusion in the study with reasons noted around lack of human focus in a database. The final studies included in the synthesis formed the point of analysis $(n=37)$. Following this, summary tables were produced, revised, adapted and reproduced and finally analysis.

Figure 1: Flowchart detailing the steps followed in selection of studies

The thirty-seven papers (see supplementary table) were analysed using content and thematic analysis. Content analysis can be used to examine any artefacts of social communication, ranging from historical documents to transcriptions of recorded verbal communication. The essential process of content analysis is to attach codes to statements, phrases or passages in categories or themes drawn from the content itself, the research questions or from the theoretical framework (Flick 2002; Minichiello 1995). Codes are a means to reorganise data to enhance analysis (Minichiello 1995). A thematic analysis was also conducted to identify prevailing research themes within the studies building on the codes. This involved carefully reading and re-reading the data in the process of theme identification (Fereday and MuirCochrane 2006). Thematic summary tables were constructed and reworked to ascertain similarities and differences in the studies.

\subsection{Theoretical framework}

A theoretical framework to inform coding and interpretation was adapted from work on ecosystem-based adaptation (EbA), noting that "ecosystem-based approaches [...] by preserving and enhancing ecosystems, enable society to better mitigate and adapt to climate change" (Munang et al. 2013: 27). The 'life support systems' (ecosystem services) that coral reefs provide to humans is at the core of what EbA seeks to protect or restore. Thus, the 'people' element is prominent in both EbA-related theory and practice. Within the socioecological system, understanding the role that various stakeholders play is central. Stakeholders whether they be the scientist's, communities, NGOs, businesses, government agencies or the funders are sources for benefits to be actualised or trade-offs to transpire.

Using the work of Nalau and Becken (2018), who analysed over one hundred EbA policy and practice documents, the main concepts, constraints and enablers of EbA were identified. Focusing specifically on constraints, Nalau et al. (2018) suggest that the following dimensions require further attention:

- Economic and Financial: relates to financing adaptation measures (including analyses that compare EbA with mainstream alternatives), but also to the wider economic context of development and poverty alleviation.

- Governance and institutions: includes institutional arrangements, policy environment and community participation.

- Social and Cultural: considers values and beliefs of local people and community, their socio-economic context, and local knowledge.

- Knowledge constraints and gaps: addresses methods used as an intervention, and lack of knowledge in particular areas (e.g. monitoring) 
Clearly, there are linkages between these dimensions, but nevertheless they provided useful starting points to inform the coding in this review. They were adapted and enhanced as new themes emerged or as it became apparent that some dimensions were covered with considerably more detail than others in the existing literature. The existing literature in addition to the insights gained from this review informed the development of a new framework presented in the 'Discussion' section.

\section{FINDINGS}

From the 37 articles coded, 19 sub-themes emerged borne largely from the EbA literature. Whilst risk is a key element in the EbA literature, it is often associated with a broader (climate) risk assessment process. In this research, risk emerged as an important aspect of the intervention itself, and it was therefore added as a theme in its own right. The 19 sub-themes were further coded resulting in seven clearly defined themes which captured the major human dimensions 'sentiments' of the 37 papers and form the basis of the results. Table 1 summarises the major findings which are discussed in detail in this section.

Table I: Results of Thematic Analysis

\subsection{Cost/benefit}

A significant focus $(n=23)$ of the review papers was on better understanding the economic parameters of coral restoration as an EbA approach, particularly the economic costs, potential co-benefits and scalability issues (Okubo and Onuma 2015). Lack of robust insights into scalability (Boström-Einarsson et al. 2018) would require data on establishment and maintenance costs of the intervention, as well as information on the true value of corals and their potential as a tradable and non-tradable commodity (Rinkevich 2015). The need to consider all cost and benefits of alternative interventions, including restoration projects, was also highlighted by Douglas (2010) who notes that Marine Protected Areas, as a key habitat protection strategy, are associated with a wide range of benefits. These often involve excluding fishing, changing operators' practices, reducing runoff into the marine environment, and zoning recreational use.

The literature provides an indication on the costs of coral restoration (Table II). Whilst, estimates and methodologies differ vastly, coral restoration is not cheap and preserving reefs is more cost-effective than restoring them (Douglas 2010). The economics of restoration depend considerably on the particular project. Based on their study of reefs in the Coral Triangle, Williams et al. (2019) suggest that coral rehabilitation in severely damaged areas under constant anthropogenic disturbances is achievable over large scales. The establishment of 11,000 structures covering $7000 \mathrm{~m}^{2}$ over $20,000 \mathrm{~m}^{2}$ of reef comes at a cost of US\$174,000. The wide range of cost estimates provided by Spurgeon $(1998 ; 2001)$ confirms more recent figures being in the order of 471,621 US\$/ha (at base year 2010) (Boström-Einarsson et al. 2018).

Table II: Various costings studies

There was evidence in the literature of cost differences of restoration in different economic contexts. Bayraktarov et al. (2016: 1055) argue that restoration is up to 30 times cheaper in developing economies due to lower cost through community or volunteer participation, although costs in developed countries could also be reduced by using volunteers in the process (Toh et al. 2017). The impact of drawing on local participants to not only reduce 
costs, but also enable long-term benefits in the face of funding constraints was confirmed for case studies in Indonesia, Panama and Palau (Goreau and Hilbertz 2008) and in the Philippines (dela Cruz et al. 2014).

Two studies illustrate a unique co-benefit potential of restoration work, beyond the immediate reef function and the direct ecological services reefs provide (Ferrario et al. 2014; Reguero et al. 2018). Ferrario et al. (2014), undertook a meta-analysis of the effectiveness of coral reefs for coastal hazard risk reduction. Reefs reduce energy waves by $97 \%$, and with over 100 million or more people benefiting from these processes, it may be more cost effective to restore reefs including active 'silviculture' than building tropical breakwaters. Moreover, reefs not only reduce coastal erosion, an impact which will only increase as sea levels rise, but the impacts of low-frequency, high-energy events such as storms and cyclones are significantly reduced compared with artificial structures.

\subsection{Socio-cultural context and benefits}

$\mathrm{EbA}$ is often considered to be particularly effective when livelihoods are wedded to ecosystems. This is often more present in developing economies where benefits of an environmental intervention support livelihoods and reduce poverty (Munang et al. 2013). Seven studies (Goreau and Hilbertz 2008; Kittinger et al. 2016; Lirman and Schopmeyer 2016; Hein et al. 2017; Trialfhianty and Suadi 2017; Hein et al. 2019) placed people centre stage by examining the socio-cultural and socio-economic aspects of active coral restoration projects. The majority of case studies in the papers reviewed were contextualised within developing economies (see Table III). Research on human aspects of coral restoration broadly reflects the geographic distribution of case studies as found by uptake of coral restoration as found by Boström-Einarsson et al. (2018), where $40 \%$ of identified projects were in the USA, Philippines, Thailand or Indonesia.

Table III: Distribution of studies across the globe

There are different ways in which the local community can participate in coral restoration projects, from aiding in the planning phase to providing spiritual contributions throughout the process (Trialfhianty and Suadi 2017). The effect of involving local communities is clearly positive in the literature (Kittinger et al. 2016; Trialfhianty and Suadi 2017; Hein et al. 2018; Hein et al. 2019). The community efforts are rewarded in the form of employment, education, stewardship, recreation and satisfaction in addition to other social and cultural benefits (Hein et al. 2019). In Hawaii, for example, at least 160 temporary and some permanent positions were created as a result of the active restoration activities (Kittinger et al. 2016).

In order to implement a restoration strategy in a community and to obtain the desired social benefits it is necessary to respect the customs and beliefs that some traditional communities have, as exemplified by Ulunihau (2009). In a case study in Fiji, villagers showed a deep understanding of nature: they believe that all living creatures are interrelated, and everyone is responsible for them. Additionally, restrictions on fishing grounds are only allowed by elders and chiefs from the community, so earning their permission is fundamental. By respecting these cultural nuances in Fiji, the restoration project reported on by Ulunihau (2009) was integrated in the society and it progressed until the ecological results where obvious. Bottema and Bush (2012) also explain the importance of respecting culture and gaining the community's support through encouraging their traditions. In their case study in Bali they reveal how some businesses funded the rehabilitation of local temples and spiritual 
ceremonies. By doing so, they gained the rapport and trust of the religious leaders that exert a strong influence over the community and who subsequently consented for coral restoration activities.

\subsection{People central for success}

The educational benefits of active coral restoration to tourists who participate or engage with 'restored' reefs is highlighted by Ulunihau (2009), Bottema and Bush (2012), Okubo and Onuma (2015), Hein et al. (2018) and Hein et al. (2019). The common theme in the papers is that there is an increase in environmental awareness in those who decide to voluntarily participate in restoration projects. Getting people physically involved, in particular, increases understanding of the ecological problems and encourages them to engage in the solution (Hein et al 2019). Fine et al. (2019) propose Citizen Science as a method to educate people living around the Red Sea about the need to protect and restore corals.

Voluntourism in coral restoration was pitched as one factor to success by the authors in a project in Koh Tao, Thailand (Hein et al. 2018). This project, as well as other initiatives that have socio-cultural and economics outcomes for the host initiative as well as tourists (such as those discussed in Ulunihau (2009), Bottema and Bush (2012), and Hesley et al. (2017)), employs volunteers, most of whom are tourists, to implement scientific-based activities for the restoration of coral reefs. As noted earlier, the added benefit is lowering the costs of the restoration efforts (Hesley et al. 2017; Hein et al. 2018; Hein et al. 2019).

Gaining people's trust is necessary to ensure their long-term support since the suspicion of local groups or fishermen (Bottema and Bush 2012) or loss of broader interest in the project are known causes of failure (Lirman and Schopmeyer 2016). Therefore, project managers of coral restoration, beyond establishing trust, need to maintain it and meet community expectations (Hein et al. 2019). This can be achieved by working with senior leaders who could act as 'a bridge' between governments, agencies or the scientific community and members of the local community (Trialfhianty and Suadi 2017). Hein et al. (2017) propose a set of socio-cultural and economic indicators to monitor the performance of the restoration projects, one of which would be satisfaction. Perception of the project and satisfaction with it are intimately intertwined with the degree of interaction in the project, the demographic features of the region and overall project results (Trialfhianty and Suadi 2017). Centrally, feeling ownership over the project is likely to drive success.

Direct buy-in is paramount to people's contribution and the project's success. Thus, local communities find their motivation to restore reefs in the same way that many private businesses participate to profit from the activities (Bottema and Bush 2012; Meyers 2017; Okubo and Onuma 2015). This viewpoint is backed by Goreau and Hilbertz (2008) who reflect on the value of nature in "modern" ideologies. They declare that these ideologies "...value nature not for its own sake but only insofar as it is exploited to yield immediate returns". Thus, making sure that restoration projects are a suitable option to improve or maintain the local livelihood can be an approach to ensure the durability of the project.

\subsection{Tourism and its complexities}

The central role of coral reefs for tourism, and the associated economic wealth created as a result, is well understood and mapped (The Nature Conservancy 2017). Whilst marine environments and reefs provide multiple tourism opportunities, snorkelling and scuba diving are the most common activity in this environment (Garrod and Gössling 2008, cited in Meyers 2017). As such the survival of reefs is a key driver of tourism businesses and 
operators as their business depends on the reef as a commodity, but possibly, the reverse is true as well.

Many of the studies in this review (Bottema and Bush 2012; Hein et al. 2018; Fine et al. 2019) support a view that the touristic attractiveness of reefs can be used as an incentive to aid coral reef restoration efforts through visitors' direct involvement (Hesley et al. 2017; Hein et al. 2018; Hein et al. 2019). Opportunities exist for tourists and related companies to participate as a 'workforce' in accomplishing the active restoration efforts (Meyers 2017; Fine et al. 2019), increasing the durability and sustainability of the coral restoration project (e.g. Trialfhianty and Suadi 2017). Involving the private sector, including by stimulating entrepreneurial activity, is not only an effective form of local participation but also contributes to the generation of local livelihoods (Ulunihau 2009). The lack of local partnerships and poor coordination observed within case study communities, however, appears to be a major barrier to the successful involvement of tourism stakeholders (Bottema and Bush 2012; Meyers 2017; Hein et al. 2019).

The literature does offer some insightful case studies, both in terms of success, particularly in reference to the socio-cultural benefits of restoration (Hein et al. 2019) and some cause for concern. Fine et al. (2019), for example, show how the development of touristic human activities around coral reefs can be ecologically unsustainable if not carefully considered and appropriately managed. Meyers (2017) also questions the ostensible benefits of integrating restoration and tourism, given that coral restoration involves further manipulation of the environment. The juxtaposition of tourists as threat/opportunity is not new to tourism (Budowski 1976), and indeed represents one key motivator for protecting the natural resource in the first place.

The motivation of tourists engaging in such restoration efforts can be critically questions as tourist might be relieving their so-called environmental anxieties, fighting the same environmental problems that they are causing (Meyers 2017). In this sense, tourist-related restoration projects are similar to carbon offsetting programs where travellers buy themselves out of their environmental responsibilities. In the coral context "...this type of restoration work achieves satisfaction by producing a bundled experience rather than a guaranteed ecological outcome" (Meyers 2017: 210). This viewpoint suggests that some projects could be motivated by commercial reasons, and that means that the ecological integrity needs to be managed with vigilance.

The notion that businesses are first and foremost about profitability rather than conservation was levelled by Bottema and Bush (2012), Meyers (2017) as well as Okubo and Onuma (2015). The necessity to make profit highlights the need to assess projects both in terms of ecological and economic success. Relying only on ecologically conscious businesses (like the example described by Okubo and Onuma 2015) could negatively affect the effectiveness of large-scale restoration efforts. Even if tourism businesses are centrally about profit, their profitability is tied up in the ecological health of the reefs they rely upon. By building and establishing partnerships (Forsman et al. 2018) with scientists to ensure that any resort reef restoration work is best practice will provide dividends to the tourism businesses themselves and support the ecological integrity of reef system.

\subsection{Policy, governance and financing}

The review identified a major gap in studies on the policy environment as a key enabler or constraint to restoration work (only $n=1$ study directly identified with in reference to policy 
and governance and no study directly addressed financing in this theme). Given the momentum around coral restoration, more research is needed to examine the policy, governance and institutional environment and how they interact. The only paper exploring the regulatory environment was in the context of the Great Barrier Reef (Fidelman et al. 2019), a relatively highly regulated reef ecosystem. This study found that coral restoration and emerging technologies may not entirely fit in existing legislative or regulatory environments as there is significant fragmentation and duplication in the context of Australia. No research could be identified on the policy context of coral restoration in those countries that appear to lead in terms of number of projects implemented (see Table III).

Financing is complex and the main private sources of funding have been in-kind and financial donations for the NGO sector (Goreau and Hilbertz 2008), but businesses are increasingly relevant in financing restoration projects (Bottema and Bush 2012). Resorts and dive operators play a substantial role in this matter as is exemplified by Okubo and Onuma (2015) in their case study in Okinawa where some diving operators apply fees for the tour services provided that are used to cover restoration expenses. Another example is given by Ulunihau (2009) who reports a restoration project in a Fijian resort where visitors were offered the option to sponsor and plant corals. Rogers et al. (2015) propose that coral restoration is most successful in low complexity reefs and particularly in 'house reefs' where dive resorts and hotels benefit from the positive impacts of the coral restoration process.

In addition to local tourist ventures financing coral restoration activities, non-local entities also contribute to coral restoration as it is illustrated by Goreau and Hilbertz (2008) and Williams et al. (2019) in their case studies. In these examples the Global Coral Reef Alliance, an international NGO, GCRA and Mars Symbioscience, a philanthropic foundation of Mars, perform restoration efforts seeking to aid the local community with coral restoration from a non-commercial angle. Yet, both studies support the assertion made by Bottema and Bush (2012) about the relevance of local participation since the lack of significant funding needs to be compensated by voluntary work (see above). Some authors doubt the capability of local people to contribute in a meaningful way. Goreau and Hilbertz (2008), for example, raised concerns about communities' ability to handle funds. In addition, scientists do not always trust people to work on the reef effectively since community members usually do not have specialist skills and experiences (Hein et al. 2018).

The argument for coral restoration in small islands has been put forward (Duprey et al. 2017), where cost as a critical factor for scalability may be reduced, where so many people live in such proximity to the coast and reefs act as natural infrastructure. Reguero et al. (2018) suggests that climate adaptation funds could even be tapped into by developing countries for both passive and active restoration of reefs due to their value to people, livelihoods and poverty reduction.

\subsection{Evaluation}

A Restoration of Coral Reef Framework borne from combining Ostrom Framework for analysing socio-ecological systems and Kittinger et al.'s (2016) human dimensions framework of coral reefs socio-ecological systems was developed by Uribe-Castañeda et al. (2018). Coral reef restoration project designs and evaluations tend to be restricted to an ecological perspective, and to address this gap, they added the social, political and economic dimensions in the Restoration of Coral Reef Framework. By doing so better societal outcomes from restoration activities are feasible if followed (Uribe-Castañeda et al. 2018). 
There is a need for credible and agreed metrics on measuring success and return on investment (Suggett et al. 2019) and effort as well as improved documentation of failures Hein et al. (2017; 2019). Their major argument is that too often only one or two ecological indicators are used, and that measurement typically only occurs over the initial establishment phase (Hein et al 2019). What is needed is a consistent measurement of ecological health over long-term post-establishment phase, noting that "success rates reported in the scientific literature could be biased towards publishing successes rather than failures" Bayraktarov et al. (2016: 1055). Such sentiments elucidate that consensus needs to be established to provide comparable measures of success and failure and determine unit cost of active coral restoration more effectively. Further to proposed ecological indicators, Hein et al. (2017) argue for four socio-cultural and economic indicators: reef user satisfaction, stewardship, capacity-building, and economic value.

\subsection{Risks for managing reefs}

Four papers explored the risks for managing reefs now and in the future (Rogers et al. 2015; McLeod et al. 2019; Hughes et al. 2017b; Hoegh-Guldberg et al. 2018). These risks include those that arise at the macro level when attempting to manage the overall reef system. Microscale risks can also arise when implementing EbA in place. These macro and micro risks are discussed in turn.

The overarching, macro-scale risk for managing reefs is the lack of consideration of underlying drivers of ecosystem function and coral degradation or loss that form part of accelerating pressures in the Anthropocene. All four papers pointed to the need for reef health to be examined in terms of the broader socio-ecological systems in which they are situated, including economies, places and complex relationships with people (Rogers et al. 2015; McLeod et al. 2019; Hughes et al. 2017b; Hoegh-Guldberg et al. 2018). The socio-ecological approach needs to be embedded within reef management by linking resilience of the reef ecosystem to places, people, politics, and economies (Hughes et al. 2017b). Understanding drivers, dynamics systems and tipping points to avoid collapse, are crucial to such endeavours. McLeod et al. (2019) argue for investment in experimental approaches to support reef resilience (e.g. via assisted evolution).

In the context of future coral reef management, one risk is that current strategies tend to set goals based on the past 'state' of reef functions and services, instead of anticipating and preparing for future changes (Rogers et al. 2015). Returning to the original state of reefs $-\mathrm{a}$ nostalgic past state - is unrealistic, moving the focus on maintaining essential biological functions of reefs (Hughes et al. 2017b). Given the changes and new conditions that reefs face, governance systems and the management of reefs will need continuous adaptive management (Rogers et al. 2015).

The papers in this review also raise several micro-scale risks relating to coral restoration as an intervention. Any EbA that involves some level of ecosystem manipulation needs to ensure that new 'technology' does not create new problems, and instead ensure that the risk of unintended outcomes is reduced (Meyers 2017). Additionally, the risk that the perceived solution distracts from investing into more profound or systemic interventions needs to be managed. Restoration projects contain an emotional dimension as they provide hope to some people, whilst others might see them as a signal of triage and loss. Hughes et al. (2017b) argue that "[e]fforts are typically focused on restoring populations of depleted species such as turtle or targeted corals, often without adequately addressing the drivers that caused their decline in the first place" (p. 88). Such assessment implies both ethical and political 
dimensions that would benefit from further research to understand better how funds and efforts are allocated.

The authors offer multiple opportunities for action, including active coral restoration which they believe is limited in its potential scalability, including building institutions of governance, acclimatization and adaption of corals through assistance, fostering innovative partnerships, changing social norms. Crucially they argue that human psychology needs to be incorporated into any governance approach to bear "...the seriousness of the challenges without generating hopelessness or despair" (Hughes et al. 2017b: 88).

Hoegh-Guldberg et al. (2018) recognise that given the myriad of challenges faced by the global reef 'system', it is necessary to implement multiple and complementary management measures of which restoration could be one, and conservation of hot spots (and triage) might be another. Deciding on these key spots is a human decision - and therefore presents risks highlighting the need for understanding priorities, trade-offs and co-benefits. McLeod et al. (2019) suggest there is always risk with adaptation and triage, and how to decide on what is needed when and where is a complex matter, but this must be evaluated against extinction and loss and we must keep an open mind and evaluate all management options as not to endanger agile responses in the Anthropocene.

\section{DISCUSSION}

The aim of this review was to ascertain the current state of knowledge on the human dimensions of coral restoration as an EbA initiative. From reviewing the relevant literature, 37 papers were identified that covered human aspects of coral restoration. In conjunction with broader literature on ecosystem-based interventions (Nalau et al. 2018; Wamsler et al. 2016; USAID 2017), a conceptual model emerged that usefully underpins the themes identified in the coding process.

In an iterative process of coding and anchoring in literature, it became clear that existing models from EbA need to be complemented by drawing on models of technology transfer and adoption of adaptation technologies. Whilst constituting an ecosystem-based intervention, coral restoration also represents a manipulation of natural processes by means of new 'technologies'. This means that the diffusion of such new methods might follow a model developed by Biagini et al. (2014) about technology transfer and adoption within the mitigation and adaptation context. By looking at the long-term impacts of the adaptation as well as the larger social context, markets, political systems, users, perceived usefulness, costs, and broader systems can greatly enhance transfer and adoption. To integrate these aspects, theoretical models of environmental decision making (EDM) were found to be highly relevant to conceptualising and categorising social science research into coral restoration. The COBRA model of costs, opportunities, benefits, and risk analysis (New Zealand Ministry of Environment 2017) was found to useful fill the remaining gaps particularly in terms of risk and monitoring and evaluation to arrive at our final framework.

The proposed conceptual framework is visualised in Figure 2 and integrates the above three earlier models, as well as the themes presented in Table 2 earlier. The 'Human Dimensions of Coral Restoration Technology Adaptation' framework begins with conceptualising coral restoration as the new technology (1) that requires risk assessment (2) both in terms of location-specific aspects, systemic risks and broader societal considerations (e.g. Rogers et al. 2015). While all risks may not be readily identified, it is crucial that the policy environment 
and regulatory frameworks are anticipatory and agile. A more detailed debate on the ethics associated with coral restoration is outstanding and presents an important research gap that needs to be addressed in further research. In practice, these issues are recognised, and attempts are made to ensure high ethical standards of restoration projects, for example through the Code of Ethics promoted by the Coral Restoration Consortium (2020). This will become more salient with further engineered approaches such as designing or assisted evolution of reefs (Van Oppen et al. 2017; Mascarelli 2014; Hughes et al. 2017b; McLeod et al. 2019) gaining traction in countries such as Australia.

Figure 2: 'Human Dimensions of Coral Restoration Technology Adaptation' Framework.

The cost/benefits and co-benefits (3) are intimately connected to the socio-cultural context (4) of coral restoration. This review illustrates coral restoration is multifaceted - cost and benefits varying considerably in different contexts and debate exists in terms of reef value, traditional reef management techniques, and opportunity-costs of coral restoration (e.g. Okubo and Onuma 2015; Williams et al. 2019). While on face value coral restoration seems more viable in developing economies, due to reduced labour costs and significant co-benefits such acting as tropical breakwaters, there is no simple defined metrics to prove this. While numerous authors argue that it may be more realistic in these contexts with volunteers, tourists and Citizen Scientists playing a role, scalability is possible in developed economies too.

'House reefs', that is those reefs boarding resorts, do have the impetus to implement such initiatives for self-sustainment as tourism operators have the capital, possible volunteers and economic impetus to do so. Tourism stakeholders have a core logic, drawing on the symbiotic effect between healthy environments and thriving tourism industries (Liburd and Becken 2017). The co-benefits in the context of tourism is more directly apparent than large scale coral restoration costed out over huge areas. The findings provide further evidence of the close relationship between tourism and conservation (e.g. see also The Nature Conservancy 2017), although - as in other contexts - sound management is required to harness the benefits that tourism might bring, whilst minimising its negative impacts (Budowski 1976).

In terms of the socio-cultural context, furthering this work, we postulate that issues such as gender, power and cultural considerations should be more broadly embraced (McNamara et al. 2020) by the scientific community engaging in active coral restoration particularly because it is seen to be often more feasible in developing Small Island State economies (Reguero et al. 2018). This is apparent in the findings of the role of community buy-in, local ownership, and building trusting relationships and incorporating local knowledge systems into the restoration process. During the implementing phase (5), managing conflict (6) and building trust and maintaining expectations are essential (Bottema and Bush 2012; Hein et al. 2019; Lirman and Schopmeyer 2016; Trialfhianty and Suadi 2017). Building on Hein et al. (2017), if restoration is to take place in developing economies or with indigenous communities, then livelihood issues and analysis that incorporate power dynamics are culturally appropriate and gender inclusive needs to be considered. The inclusion of local or indigenous knowledge (Nalau et al. 2018) can also advance trust and mutual understanding.

Particularly apparent in the reviewed articles were stakeholders, the central zone of the model, and stakeholder's perceptions of active restoration. All stakeholders, the centre of the 
model, play such a pivotal role in maintaining success and scaling up (7) of coral restoration, from providing opportunities for scalability, their direct involvement as a community, as a tourist or as a business that has impacts on increasing the success rate of these projects (Hein et al. 2019; Boström-Einarsson et al. 2020). Balancing competing demands and livelihood strategies of all stakeholders and managing conflict between the diverse interests of stakeholders becomes of paramount importance. Evident in this review is that even if appropriately financed, the policy and governance environment is struggling to keep abreast of this fast-moving environment (Fidelman et al. 2019).

Success, determined by evaluation (8) is a difficult end point to gauge, noting that success is yet to be systematically defined and agreed and might carry some value judgement of what is important (Boström-Einarsson et al. 2020). There is a tendency in many fields, to highlight success and under-report failure (Westoby et al. 2020, forthcoming). The lack of monitoring and evaluation of EbA projects more broadly was identified as a key constraint to future success (Nalau et al. 2018). What is clearly needed are parameters to benchmark success and failure consistently and remember that success or failure need to be measured beyond the immediate 2-3-year project cycle. For coral restoration, maintaining success and scalability requires local community, stewardship, citizen science, and tourism (Hein et al. 2020). This can have the effect of both providing hope and alleviate 'anxieties' that we are intervening in their demise. Weighing up the 'risk' and considering systems-thinking and ethics suggests the need to address the drivers of reef decline to complement active reef restoration.

The insights from this review are significant. We must continue to better measure the true value of reef systems; in terms of all the goods and services, they provide their whole utility and value. We also need credible and agreed metrics on measuring success and return on investment and effort as well as improved documentation of failures. This needs to be established and wholly determined, so that active coral restoration may be contextualised and tested at various scales as an EbA approach. As new physical science emerges, the potential exists for a wider adoption, particularly coupled with resorts and in communities who can invest time in their reefs for their own livelihood strategies.

\section{CONCLUSION}

This paper is the first to systematically explore the state of knowledge across the whole loop of the 'Human Dimensions of Coral Restoration Technology Adaptation'. The framework was developed by building on both theoretical and practical knowledge advanced in the field of ecosystem-based interventions to manage change. People are central to the Anthropocene, are central drivers of reef decline, and are ultimately central to their protection and restoration. Ethically we need to weigh up from the start our role in driving solutions prior to intervention and we need to place the diversity of stakeholders in a balanced tension for success to become a reality on the ground. The time for passive intervention is no longer viable, but active does not mean reactive. It means replicable, measures and cautions proactive approaches that not only ensure an ongoing learning process, but also function as beacons of optimism and hope in a world of accelerating environmental crisis.

Understanding the human dimensions of coral restoration is critically important and conceptualising this intervention as a new technology provides a path for assessing the microand macro-risks. Whilst the science of active reef restoration approaches was not the purpose of this review, there is a risk that politicians support funding directions and scientist and practitioners of coral restoration might seize the opportunity, without however addressing 
underlying root causes (Hughes et al. 2017b). Within Australia, the government is investing in active restoration efforts with $\$ 100$ million dollars being injected in the Great Barrier Reef in 2018 (Great Barrier Reef Foundation 2018). Such investment needs to consider risks but also carefully weigh the cost and benefits of such new technologies. Local people and communities, including leaders that act as gatekeepers, are particularly influential in shaping the success of these restoration projects, alongside the scientists envisioning these interventions, financial supports, businesses and tourists to those sites. Managing these stakeholders as well as the governance arrangements to enable long-term restoration to be actualised without conflict is essential.

\section{Acknowledgements}

Funding for this research has been provided by the National Environmental Science Program Tropical Water Quality Hub (Project 5.5) and Griffith University 


\section{LITERATURE CITED}

Anthony K, Bay LK, Costanza R, Firn J, Gunn J, Harrison P, Heyward A, Lundgren P, Mead D, Moore T, Mumby PJ, van Oppen MJH, Robertson J, Runge MC, Suggett DJ, Schafelke B, Wachenfeld D, Walshe T (2017) New interventions are needed to save coral reefs. Nature Ecology \& Evolution 1:1420-1422. doi: 10.1038/s41559-0170313-5 29185526

Bayraktarov E, Saunders MI, Abdullah S, Mills M, Beher J, Possingham HP, Mumby PJ, Lovelock CE (2016) The cost and feasibility of marine coastal restoration. Ecological Applications 26(4):1055-1074. doi:10.1890/15-1077

Biagini B, Kuhl L, Gallagher KS, Ortiz C (2014) Technology transfer for adaptation. Nature Climate Change 4:828-834. doi: 10.1126/science.345.6197.634-

Boström-Einarsson L, Babcock RC, Bayraktarov E, Ceccarelli D, Cook N, Ferse SCA, Handcock B, Harrison P, Hein M, Shaver E, Smith A, Suggett D, Stewart-Sinclair PJ, Vardi T, McLeod IM (2020) Coral restoration - A systematic review of current methods, successes, failures and future directions. PLoS ONE 15(1):1-20. doi: 10.1371/journal.pone.0226631

Boström-Einarsson L, Ceccarelli D, Babcock RC, Bayraktarov E, Cook N, Harrison P, Hein M, Shaver E, Smith A, Stewart-Sinclair PJ, Vardi T, McLeod IM (2018) - Coral restoration in a changing world - A global synthesis of methods and techniques, report to the National Environmental Science Program. Reef and Rainforest Research Centre Ltd, Cairns (63pp.).

Bottema MJM, Bush SR (2012) The durability of private sector-led marine conservation: A case study of two entrepreneurial marine protected areas in Indonesia. Ocean \& Coastal Management 61:38-48. doi:10.1016/j.ocecoaman.2012.01.004

Brander LM, Wagtendonk AJ, Hussain SS, McVittie A, Verburg PH, de Groot RS, van der Ploeg S (2012) Ecosystem service values for mangroves in Southeast Asia: A metaanalysis and value transfer application. Ecosystem Services 1(1):62-69. doi:10.1016/j.ecoser.2012.06.003

Budowski G (1976) Tourism and Environmental Conservation: Conflict, Coexistence, or Symbiosis? Environmental Conservation 3(1):27-31. doi:10.1017/S0376892900017707

Coral Restoration Consortium (2020) Coral Restoration Consortium Code of Ethics. https://crc.reefresilience.org/resources/code-of-ethics/Accessed 18 July 2020

Crisp BR (2015) Systematic reviews: A social work perspective. Australian Social Work 68(3):284-295. doi:10.1080/0312407X.2015.1024266

dela Cruz DW, Villanueva RD, Baria MVB (2014) Community-based, low-tech method of restoring a lost thicket of Acropora corals. ICES Journal of Marine Science 71(7): 1866-1875. doi:10.1093/icesjms/fst228. 
Douglas AJ (2010) The costs and benefits of developing sustainable use strategies and restoration activities for corals and coral reefs. In Davin TB and Brannet AP (eds) Coral Reefs: Biology, Threats and Restoration. Nova Science Publishers, Colorado, pp 53-75

Duprey NN, McIlroy SE, Ng TPT, Thompson PD, Kim T, Wong JCY, Wong CWM, Husa SM, Li SMH, Williams GA, Bake DM (2017) Facing a wicked problem with optimism: issues and priorities for coral conservation in Hong Kong. Biodiversity and Conservation 26(11):2521-2545. doi:10.1007/s10531-017-1383-z

Fereday J, Muir-Cochrane E (2006) Demonstrating Rigor Using Thematic Analysis: A Hybrid Approach of Inductive and Deductive Coding and Theme Development. International Journal of Qualitative Methods 5(1):80-92. doi:10.1177/160940690600500107

Ferrario F, Beck MW, Storlazzi CD, Micheli F, Shepard CC, Airoldi L (2014) The effectiveness of coral reefs for coastal hazard risk reduction and adaptation. Nature 5: 3794. doi:10.1038/ncomms4794

Fidelman P, McGrath C, Newland M, Dobbs K, Jago B, Hussey K (2019) Regulatory implications of coral reef restoration and adaptation under a changing climate. Environmental Science and Policy 100:221-229, doi:10.1016/j.envsci.2019.04.016

Fine M, Cinar M, Voolstra CR, Safa A, Rinkevich B, Laffoley D, Hilmi N, Allemand D (2019) Coral reefs of the Red Sea - Challenges and potential solutions. Regional Studies in Marine Science 25:100498. doi:10.1016/j.rsma.2018.100498

Flick U (2002) Qualitative Research - State of the Art. Social Science Information 41(1):524. doi:10.1177/0539018402041001001

Forsman ZH, Maurin P, Parry M, Chung A, Sartor C, Hixon MA, Hughes K, Rogers K, Knapp ISS, Gulko DA, Franklin EC, Del Rio Torres L, Chan NT, Wolke CS, Gates RD, Toonen RJ (2018) The first Hawai' $i$ workshop for coral restoration \& nurseries. Marine Policy 96:133-135. doi:10.1016/j.marpol.2018.08.009

Garrod B, Gössling S (2008) New frontiers in marine tourism: Diving experiences, sustainability, management. Routledge, Oxford

Gomez ED (1983) Perspectives on coral reef research and management in the Pacific. Ocean Management 8(4):281-295. doi:10.1016/0302-184X(83)90008-2

Goreau TJ, Hilbertz W (2008) Bottom-Up Community-Based Coral Reef and Fisheries Restoration in Indonesia, Panama, and Palau. In France R (ed) Handbook of Regenerative Landscape Design. CRC Press, Boca Raton, pp 143-159

Guitart D, Pickering C, Byrne J (2012) Past Results and Future Directions in Urban Community Gardens Research. Urban Forestry \& Urban Greening 11(4):364-373. doi: 10.1016/j.ufug.2012.06.007 
Great Barrier Reef Foundation (2018). Record Investment in the Great Barrier Reef to drive jobs https://www.barrierreef.org/news/media-release/record-investment-in-the-greatbarrier-reef Accessed 10 April 2020

Hein MY, Newlands M, Elms A, Vella K, McLeod IM (2020) Why do Great Barrier Reef tourism operators engage in coral restoration? An exploration of motivations, opportunities, and challenges. Report to the National Environmental Science Program. Reef and Rainforest Research Centre Limited, Cairns (24 pp.).

Hein MY, Birtles A, Willis BL, Gardiner N, Beeden R, Marshall NA (2019) Coral restoration: Socio-ecological perspectives of benefits and limitations. Biological Conservation 229:14-25. doi:10.1016/j.biocon.2018.11.014

Hein MY, Couture F, Scott CM (2018) Ecotourism and coral reef restoration: Case studies from Thailand and the Maldives. In Prideaux B. and Pabel A (ed) Coral Reefs: Tourism, Conservation and Management. Routledge, Abingdon, pp 137-150 doi: $10.4324 / 9781315537320$

Hein MY, Willis BL, Beeden R, Birtles A (2017) The need for broader ecological and socioeconomic tools to evaluate the effectiveness of coral restoration programs. Restoration Ecology 25(6):873-883. doi:10.1111/rec.12580

Heron S, van Hooidonk R, Maynard J, Anderson K, Day J, Geiger E, Hoegh-Guldberg O, Hughes T, Marshall P, Obura D, Eakin CM (2018) Impacts of Climate Change on World Heritage Coral Reefs: Update to the First Global Scientific Assessment. Paris, UNESCO World Heritage Centre.

Hesley D, Burdeno D, Drury C, Schopmeyer S, Lirman D (2017) Citizen science benefits coral reef restoration activities. Journal for Nature Conservation 40:94-99. doi:10.1016/j.jnc.2017.09.001

Hoegh-Guldberg O, Kennedy EV, Beyer HL, McClennen C, Possingham HP (2018) Securing a Long-term Future for Coral Reefs. Trends in Ecology \& Evolution 33(12):936-944. doi:10.1016/j.tree.2018.09.006

Hughes TP, Kerry JT, Álvarez-Noriega M, Álvarez-Romero JG, Anderson KD, Baird AH, Babcock RC, Beger M, Bellwood DR, Berkelmans R, Bridge TC, Butler IR, Byrne M, Cantin NE, Comeau S, Connolly SR, Cumming GS, Dalton SJ, Diaz-Pulido G, Eakin CM, Figueira WF, Gilmour JP, Harrison HB, Heron SF, Hoey AS, Hobbs JA, Hoogenboom MO, Kennedy EV, Kuo C, Lough JM, Lowe RJ, Liu G, McCulloch MT, Malcolm HA, McWilliam MJ, Pandolfi JM, Pears RJ, Pratchett MS, Schoepf V, Simpson T, Skirving WJ, Sommer B, Torda G, Wachenfeld DR, Willis BL, Wilson SK (2017a) Global warming and recurrent mass bleaching of corals. Nature 543:373377. doi: 10.1038/nature21707 28300113

Hughes TP, Barnes ML, Bellwood DR, Cinner JE, Cumming GS, Jackson JBC, Kleypas J, van de Leemput IA, Lough JM, Morrison TH, Palumbi SR, van Nes EH, Scheffe M (2017b) Coral reefs in the Anthropocene. Nature 546:82-90. doi:10.1038/nature22901

Kittinger JN, Bambico TM, Minton D, Miller A, Mejia M, Kalei N, Wong B, Glazier EW (2016) Restoring ecosystems, restoring community: socioeconomic and cultural 
dimensions of a community-based coral reef restoration project. Regional

Environmental Change 16(2):301-313. doi:10.1007/s10113-013-0572-x

Liburd JJ, Becken S (2017) Values in nature conservation, tourism and UNESCO World Heritage Site stewardship. Journal of Sustainable Tourism 2(12):1719-1735. Doi: $10.1080 / 09669582.2017 .1293067$

Lirman D, Schopmeyer S (2016) Ecological solutions to reef degradation: Optimizing coral reef restoration in the Caribbean and Western Atlantic. Peer J 4,e2597. doi:10.7717/peerj. 2597

Maragos JE. (1974) Coral transplantation: a method to create, preserve, and manage coral reefs. Hawaii University Sea Grant Advisory Report 35 In: Thayer GW (ed) restoring the nation's marine environment. Maryland Seagrant, Maryland

Marshall NJ, Kleine DA, Dean AJ (2012) CoralWatch: Education, monitoring, and sustainability through citizen science. Ecology and the Environment 10(6):332-334. Doi: $10.1890 / 110266$

Mascarelli A (2014) Climate-change Adaptation: Designer reefs. Nature 508(7497):444-446. doi:10.1038/508444a

Mcleod E, Anthony KRN, Mumby PJ, Maynard J, Beedene R, Graham NAJ, Heron SF, Hoegh-Guldberg O, Jupiter S, MacGowana P, Mangubhai S, Marshall N, Marshall PA, McClanahan TR, Mcleod K, Nyström M, Oburar D, Parker B, Possingham HP, Salm RV, Tamelander J (2019) The future of resilience-based management in coral reef ecosystems. Journal of Environmental Management 233:291-301. doi:10.1016/j.jenvman.2018.11.034

McNamara KE, Clissold R, Westoby R, Piggott-McKellar AE, Kumar R, Clarke T, Namoumou R, Areki F, Joseph E, Warrick O, Nunn PD (2020) An assessment of community-based adaptation initiatives in the Pacific Islands. Nature Climate Change 10:628-639. doi:10.1038/s41558-020-0813-1

Meyers R (2017) An aesthetics of resilience: design and agency in contemporary coral restoration. Resilience 5(3):201-221. doi:10.1080/21693293.2016.1241477

Minichiello V (1995) In-depth interviewing: principles, techniques, analysis. Longman, Melbourne

Morrison TH, Hughes TP, Ager WN, Brown K, Barnett J, Lemos MC, Huitema D, Huchery C, Chaigneau T, Tuner R, Hettiarachchi M (2019) Safe reefs to rescue all ecosystems. Nature 573:333-336. doi: 10.1038/d41586-019-02737-8

Munang R, Thiaw I, Alverson K, Mumba M, Liu J, Rivington M (2013) Climate change and Ecosystem-based Adaptation: a new pragmatic approach to buffering climate change impacts. Current Opinion in Environmental Sustainability 5(1):67-71. doi:10.1016/j.cosust.2013.02.002

Nalau, J., Becken, S. (2018). Ecosystem-based Adaptation to Climate Change: Review of Concepts. Griffith Institute for Tourism Research Report No 15 
https://www.griffith.edu.au/_data/assets/pdf_file/0029/553475/Nalau-and-

BeckenS_PGIFTreport_Final_2018.pdf Accessed 10 March 2020

Nalau J, Becken S Mackey B (2018) Ecosystem-based adaptation: A Review of the Constraints. Environmental Science and Policy 89:357-364. doi:

10.1016/j.envsci.2018.08.014

New Zealand Ministry of Environment (2017). Natural Resource Framework: COBRA. New Zealand Government. https://www.mfe.govt.nz/about-us/our-policy-and-evidencefocus/enhancing-our-policy-advice Accessed 12 April 2020

Ng CSL, Toh TH, Chou LM (2017) Artificial reefs as a reef restoration strategy in sedimentaffected environments: Insights from long-term monitoring. Aquatic Conservation: Marine and Freshwater Ecosystems 27:776-985. 10.1002/aqc.2755

Nikulina V, Simon D, Ny H, Baumann H (2019) Context-Adapted Urban Planning for Rapid Transitioning of Personal Mobility towards Sustainability: A Systematic Literature Review. Sustainability 11(4):1007. doi:10.3390/su11041007

Obolski U, Hadany L, Abelson A (2016) Potential contribution of fish restocking to the recovery of deteriorated coral reefs: An alternative restoration method? PeerJ 4:e1732. doi:10.7717/peerj.1732

Okubo N, Onuma A (2015) An economic and ecological consideration of commercial coral transplantation to restore the marine ecosystem in Okinawa, Japan. Ecosystem Services 11:39-44. doi:10.1016/j.ecoser.2014.07.009

Pickering C, Byrne J (2014) The benefits of publishing systematic quantitative literature reviews for $\mathrm{PhD}$ candidates and other early career researchers. Higher Education Research and Development 33:534-548 doi:10.1080/07294360.2013.841651

Pickering C, Grignon J, Steven R, Guitart D, Byrne J (2015) Publishing not perishing: How research students transition from novice to knowledgeable using systematic quantitative literature reviews. Studies in Higher Education 40(10):1756-1769. doi: 10.1080/03075079.2014.914907

Possingham HP, Bode M, Klein CJ (2015) Optimal conservation outcomes require both restoration and protection. PLoS Biol 13(1):e1002052. doi:

10.1371/journal.pbio.1002052

Reguero BG, Beck MW, Agostini VN, Kramer P, Hancock B (2018) Coral reefs for coastal protection: A new methodological approach and engineering case study in Grenada. Journal of Environmental Management 210:146-161.

doi:10.1016/j.jenvman.2018.01.024

Rinkevich B (2014) Rebuilding coral reefs: does active reef restoration lead to sustainable reefs?. Environmental Sustainability 7:28-36. doi:10.1016/j.cosust.2013.11.018

Rinkevich B (2015) Novel tradable instruments in the conservation of coral reefs, based on the coral gardening concept for reef restoration. Journal of Environmental Management 162:199-205. doi:10.1016/j.jenvman.2015.07.028 
Rogers A, Harborne AR, Brown CJ, Bozec Y, Castro C, Chollett I, Hock K, Knowland CA, Marshell A, Ortiz JC, Razak T, Roff G., Samper-Villarreal J, Saunders MI, Wolff $\mathrm{NH}$, Mumby PJ (2015) Anticipative management for coral reef ecosystem services in the 21st century. Global Change Biology 21(2):504-514. doi:10.1111/gcb.12725

Spurgeon JPG (2001) Improving the economic effectiveness of coral reef restoration. Bulletin of Marine Science 69(2):504-514.

Spurgeon JPG (1998) The Socio-Economic Costs and Benefits of Coastal Habitat Rehabilitation and Creation. Marine Pollution Bulletin 37(8-12):373-382. doi:10.1016/S0025-326X(99)00074-0

Steven R, Pickering C, Castley JG (2011) A review of the impacts of nature based recreation on birds. Journal of Environmental Management 92:2287-2294. doi:10.1016/j.jenvman.2011.05.005.

Suggett DJ, Camp EF, Edmondson J, Boström-Einarsson L, Ramler V, Lohr K, Patterson JT (2019) Optimizing return-on-effort for coral nursery and outplanting practices to aid restoration of the Great Barrier Reef. Restoration Ecology 27(3):683-693. doi:10.1111/rec.12916

Sully S, Burkepile DE, Donovan MK, Hodgson G, van Woesik R (2019) A global analysis of coral bleaching over the past two decades. Nature Communications 10:1264 doi:10.1038/s41467-019-09238-2

The Nature Conservancy (2017). Mapping Ocean Wealth. http://oceanwealth.org/. Accessed 12 February 2020

Toh TC, Ng CSL, Loke HX, Taira D, Toh KB, Afiq-Rosli L, Du RCP, Cabaitan P, Sam SQ, Kikuzawa YP, Chou LM, Song T (2017) A cost-effective approach to enhance scleractinian diversity on artificial shorelines. Ecological Engineering 99:1031-1045. doi:10.1016/j.ecoleng.2016.11.066

Trialfhianty TI, Suadi. (2017). The role of the community in supporting coral reef restoration in Pemuteran, Bali, Indonesia. Journal of Coastal Conservation 21(6):873-882. doi:10.1007/s11852-017-0553-1

Turner PA, Mach KJ, Lobell DB, Benson SM, Baik E, Sanchez DL, Field CB (2018) The global overlap of bioenergy and carbon sequestration potential. Climatic Change 148 :1-10. doi:10.1007/s10584-018-2189-z.

Ulunihau P (2009) Vanua domoni: coral restoration in a traditional Fijian village. In Corcoran PB and Osano PM (eds) Young people, education and sustainable development. Wageningen Academic Publishers, The Netherlands, pp 315-320.

Uribe-Castañeda N, Newton A, Le Tissier M (2018) Coral Reef socio-ecological systems analysis \& restoration. Sustainability, 10(2):4490. doi:10.3390/su10124490

USAID (2017). Restoring Coral Reefs in the Face of Climate Change in the Seychelles. file://C:/Users/s2825673/Downloads/Case\%20Study 
\%20Restoring $\% 20$ Coral $\% 20$ Reefs $\% 20$ in $\% 20$ the $\% 20$ Face $\% 20$ of $\% 20$ Climate $\% 20$ Cha nge\%20in\%20the\%20Seychelles\%202018.pdf Accessed 13 July 2020

Van Oppen MJH, Gates RD, Blackall LL, Cantin N, Chakravarti LJ, Chan WY, Cormick C, Crean A, Damjanovic K, Epstein H, Harrison PL, Jones TA, Miller M, Pears RJ, Peplow LM, Raftos DA, Schaffelke B, Stewart K, Torda G, Wachenfeld D, Weeks AR, Putnam HM (2017) Shifting paradigms in restoration of the world's coral reefs. Global Change Biology 23(9):3437-3448. doi:10.1111/gcb.13647

Wamsler C, Niven L, Beery TH, Bramryd T, Ekelund N., Jönsson KI, Osmani A, Palo T, Stålhammar S (2016) Operationalizing ecosystem-based adaptation: harnessing ecosystem services to buffer communities against climate change. Ecology and Society 21(1):31. doi: 10.5751/ES-08266-210131

Westoby R, McNamara KE (2019) Fear, grief, hope and action. Nature Climate Change 9(7) 500-501. doi:10.1038/s41558-019-0511-z

Westoby R, Rahman MF, McNamara KE, Huq S, Clissold R, Khan MR (2020) Sharing adaptation failure to improve adaptation outcomes. OneEarth October 2020, forthcoming.

Wilkinson CR (2004) Status of Coral Reefs of the World: 2004. Australian Institute of Marine Science. 572p

Williams SL, Sur C, Janetski N, Hollarsmith JA, Rapi S, Barron L, Heatwole SJ, Yusuf AM, Yusuf S, Jompa J, Mars F (2019) Large-scale coral reef rehabilitation after blast fishing in Indonesia. Restoration Ecology 27(2):447-456. doi:10.1111/rec.12866 